\title{
Heel skin hyperaemia: direct compression versus vascular occlusion
}

\author{
Harvey N. Mayrovitz, Nancy Sims and Lori Dribin \\ College of Medical Sciences, Nova Southeastern University, Ft Lauderdale, FL, USA
}

\section{Summary}

\section{Correspondence}

Dr Harvey N. Mayrovitz, College of Medical Sciences, Nova Southeastern University, 3200 S.

University Drive, Ft Lauderdale, FL 33328, USA

E-mail: mayrovit@comcast.net

\section{Accepted for publication}

Received 9 January 2003;

accepted 21 May 2003

\section{Key words}

ischaemia; laser-Doppler; microcirculation; pressure ulcer; reactive hyperaemia; skin blood flow; tissue compression; tissue oxygen
Vulnerability of the heel to ulceration in bed-bound persons is related to direct pressure-induced blood flow decreases. Periodic pressure reduction is a clinical strategy to help prevent ulcers by allowing flow-repayment hyperaemia that has a magnitude and duration thought to be related to the duration of the prior interval of ischaemia. However, there are reasons to question whether effects of flow stoppages caused by direct tissue loading are similar to those because of ischaemia without superimposed direct pressure. This question was investigated by comparing posterior heel skin blood flow responses via laser-Doppler perfusion monitoring of 27 supine-lying subjects in whom blood flow was reduced by 5 -min of direct heel loading on a support surface and by 5 -min of ankle-cuff compression. Results showed that blood flow reductions were the same for both methods but the hyperaemia was significantly greater when flow reduction was produced by direct heel loading. This was true for ratio of peak hyperaemic flow to baseline $(8.20 \pm 1.32 \mathrm{~s}$ versus $4.68 \pm 0.80 \mathrm{~s}, \quad P \leq 0.001)$, hyperaemic to baseline 3 -min flow-time area ratios $(4 \cdot 70 \pm 0.65 \mathrm{~s}$ versus $1.95 \pm 0.29 \mathrm{~s}, \mathrm{P} \leq 0.001)$ and for total hyperaemia durations (352 $\pm 39 \mathrm{~s}$ versus $181 \pm 14 \mathrm{~s}, \mathrm{P}<0 \cdot 001)$. These findings raise new questions regarding the precise physiological effects of heel and tissue loading in general, the factors that contribute to the hyperaemic response and their clinical impact and interpretation. Possible sources of the observed greater post-loading hyperaemia responses are discussed.

\section{Introduction}

Pressure ulcers associated with sustained and unrelieved pressure during extended cardiovascular, orthopaedic and other surgical procedures, as well as in other acute and long-term care settings, are an important clinical problem (Papantonio et al., 1994; Regan et al., 1995; Allman, 1997; Byers et al., 2000). Many factors contribute to this process (Kemp et al., 1990; Tourtual et al., 1997), but a final common pathway appears to be because of blood flow reductions within pressure-loaded tissue. The pressure-related blood flow deficits affect the skin breakdown process in multiple ways (Kosiak, 1976; Mayrovitz, 1998b), most often at sites of bony prominences such as sacral, greater trochanter and heel regions (Meehan, 1990; Cheneworth et al., 1994; Schoonhoven et al., 2002). The heel is particularly vulnerable to skin breakdown and ulcer development because in a supine lying person, the small amount of soft tissue between the posterior calcaneous and the surface supporting the heel, is often insufficient to buffer or disperse the local pressures experienced because of heel loading. Heel interface pressures (IP) usually exceed arterial diastolic pressure and often are close to or greater than arterial systolic blood pressure (Mayrovitz \& Sims, 2002). Systematic studies of the hyperaemic response to variable magnitudes and durations of heel loading have shown a nonlinear relation between postloading hyperaemia and the loadduration product (Mayrovitz et al., 1997; Mayrovitz \& Smith, 1998; Mayrovitz et al., 1999). Comparisons between postloading hyperaemia and maximum possible hyperaemia achieved by tissue heating, showed that heel loading of only 5 min resulted in unexpectedly high hyperaemic flows that were $80 \%$ of the maximum. As direct tissue loading produces blood flow stoppage by forces transmitted directly to underlying blood vessels whereas most methods of examining postocclusive hyperaemia use proximal limb occlusions to produce flow stoppage, we wondered if such differences give rise to differential hyperaemic response features. A recent study that compared hyperaemic responses following direct compression of the finger pad with proximal cuff occlusion of the finger, provides support for this 
possibility (Rendell \& Wells, 1998). These workers found significantly larger and longer hyperaemic responses when a 2-min flow reduction was caused by direct compression. However, it is unknown if similar differential effects are present in the clinically relevant heel tissue, which is at-risk for the effects of loading. Further, we felt it important to extend the flow stoppage duration to $5 \mathrm{~min}$ as patients who are supported by alternating pressure surfaces typically experience per cycle loading of this duration (Mayrovitz \& Smith, 1999; Evans et al., 2000; Rithalia \& Gonsalkorale, 2000; Newton, 2001; Goetz et al., 2002). Thus, our goal was to characterize and compare heel hyperaemic responses subsequent to blood flow reductions induced either by direct heel loading or by proximal blood vessel occlusion. This was accomplished by measuring and comparing posterior heel skin blood flow (laser-Doppler) in 27 supine-lying persons in whom blood flow was reduced either by 5-min of direct heel loading on the surface or by 5 -min of ankle-cuff compression.

\section{Methods}

\section{Subjects}

Twenty-seven volunteers (15 females), drawn from the medical school student and staff population, were tested after signing a consent form that was approved by the institutional review board. All subjects reported that they were in good health, none had diabetes or any other notable medical history. None were taking medications that would impact on vascular reactivity. Absence of lower extremity vascular disease was confirmed via ankle-brachial systolic pressure indices $(1.08 \pm 0.02)$. Average age was $27.5 \pm 1.4$ years (range $21-56$ years) with no age differences between females or males $(28.5 \pm 2.5$ years versus $26.5 \pm 0.7$ years, $P=0.435)$. Heights and weights were $170.2 \pm 1.8 \mathrm{~cm}$ and $72.3 \pm 2.7 \mathrm{~kg}$. All subjects had blood pressures within the normal range, with systolic, diastolic and mean blood pressures of $125 \pm 4,78 \pm 3$ and $94 \pm 36 \mathrm{mmHg}$, respectively.

\section{Heel loading and occlusion procedures}

All subjects lied supine on a standard commercially available, clinically used, air mattress with multiple air-filled cells. The support surface was modified such that the end cell on which the heels would rest could be inflated or deflated automatically under computer control. The pressure inside of this end cell was monitored and was set to its normal internal support pressure to produce heel loading for 5-min (Fig. 1a) or to zero pressure to achieve full cell deflation causing complete off-loading of the heel (Fig. 1b). To produce heel blood flow stoppage without direct pressure loading, a vascular cuff, placed around the ankle with its distal edge just proximal to the malleolus, was inflated to $180 \mathrm{mmHg}$ for $5 \mathrm{~min}$ and then rapidly released (Fig. 1c). Tests were conducted in a room with a well-controlled ambient temperature with no significant changes in room temperature
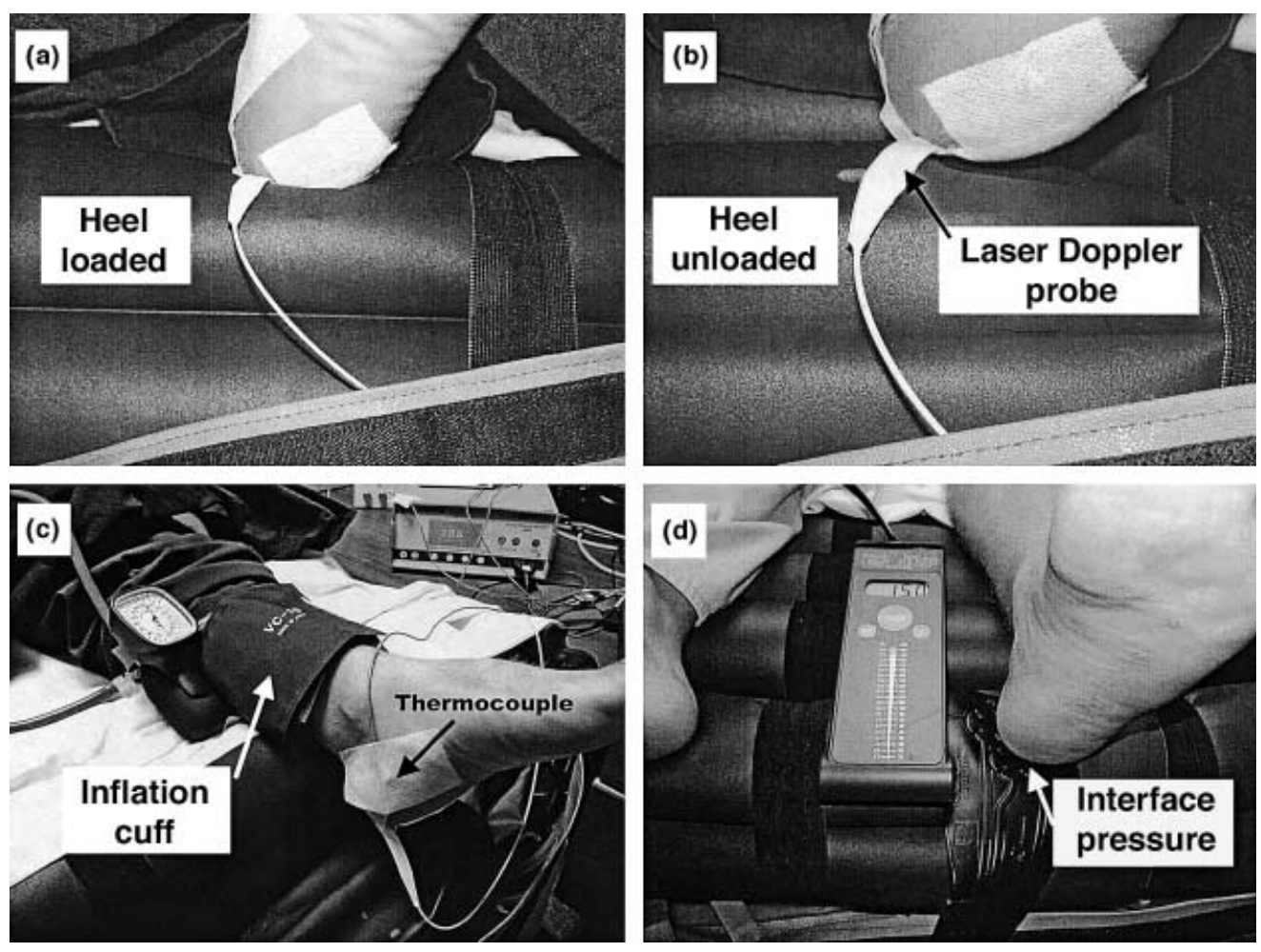

Figure 1 Heel procedures. (a) Heel loaded on support surface air filled cell; (b) heel completely unloaded by venting air in cell; (c) inflation cuff placement to produce occlusion; (d) measurement of interface pressure. 
from the start to the end of the experimental sequence $\left(23.5 \pm 0.05^{\circ} \mathrm{C}\right.$ versus $\left.23.6 \pm 0.06^{\circ} \mathrm{C}\right)$.

\section{Blood perfusion}

Heel skin blood perfusion (SBF) was monitored with a laserDoppler probe affixed to the posterior heel with tape and connected to a perfusion monitor (Vasamedics model BPM2) as previously described (Mayrovitz \& Sims, 2002). Blood perfusion is sampled to a depth of approximately $1-2 \mathrm{~mm}$. A thin probe (P-440 Soflex; Vasamedics Inc., St Paul, MN, USA; $3.6 \mathrm{~mm}$ height $\times 6.5 \mathrm{~mm}$ wide) was put on a posterior heel at the site of its contact with the support surface (Fig. 1). Laser-Doppler signals were acquired continuously throughout the experimental sequence using an instrument time constant setting of $1 \mathrm{~s}$. The acquired perfusion signals were used to determine SBF by sampling the analogue output of the perfusion monitor at 20 samples s $^{-1}$ for computer storage and off-line analysis with laser-Doppler determined SBF and reported in units of volts. Skin temperature was measured with a thermocouple (PhysiTemp, model TH-8, Clifton, NJ, USA) placed on the medial aspect of the heel (Fig. 1c). Average temperature of the skin did not significantly change during the course of the experiment being $31.5 \pm 0.6^{\circ} \mathrm{C}$ at the start and $30.9 \pm 0.5^{\circ} \mathrm{C}$ at the end. The biological zero of the laser-Doppler was determined from the ankle cuff occlusion described above and its value was subtracted from all laser-Doppler raw values as is standard (Mayrovitz, 1998a; Mayrovitz \& Leedham, 2001).

\section{Protocol sequence}

Subjects lied supine on the support surface with their heel offloaded while the laser-Doppler probe and the ankle-cuff were put into position. They were then covered with a blanket. Baseline data recording for 10 min began after they had been resting for $15 \mathrm{~min}$. Heel loading and hyperaemia were produced by fully inflating the heel cell for 5 min followed by a rapid deflation. Heel ischaemia was via ankle-cuff inflation for 5-min. The order with which direct heel loading or cuffinflation was applied was reversed in half of the subjects. In all cases there was a 15 min recovery interval between successive interventions. The two basic sequences and typical SBF response patterns are shown in Fig. 2 in which the arrow heads show the onset of hyperaemia. At the end of the experimental sequence, heel IP were measured with a pressure sensor (Thermapoint pressure monitor, ROHO Inc., Belleville, IL, USA) that was placed between the heel and the support surface (Fig. 1D). The end air-cell was pressurized to the level used during the testsequence and six measurements of IP were made and averaged. Finally, ankle and brachial systolic pressures were determined using standard Doppler ultrasound.

\section{Parameters, analysis and comparisons}

Average SBF was determined for the 10-min baseline interval $\left(Q_{B}\right.$, Fig. 3), and for the 10-min interval $\left(Q_{A V G}\right)$ that included a 5-min flow stoppage time and a 5-min hyperaemia time. The ratio $Q_{A V G} / Q_{B}$ was determined as an index of the hyperaemia 'repayment' to the 5-min blood flow deprivation. A ratio of one would indicate exact repayment in the sense that average flow for combined ischaemic and hyperaemic intervals equals average flow during the 10-min baseline. A direct index of relative hyperaemia is the ratio of the flow-time area under the hyperaemic response to the area under the base interval for corresponding time intervals. These were determined for the immediate 3-min prior to ischaemia and for the immediate

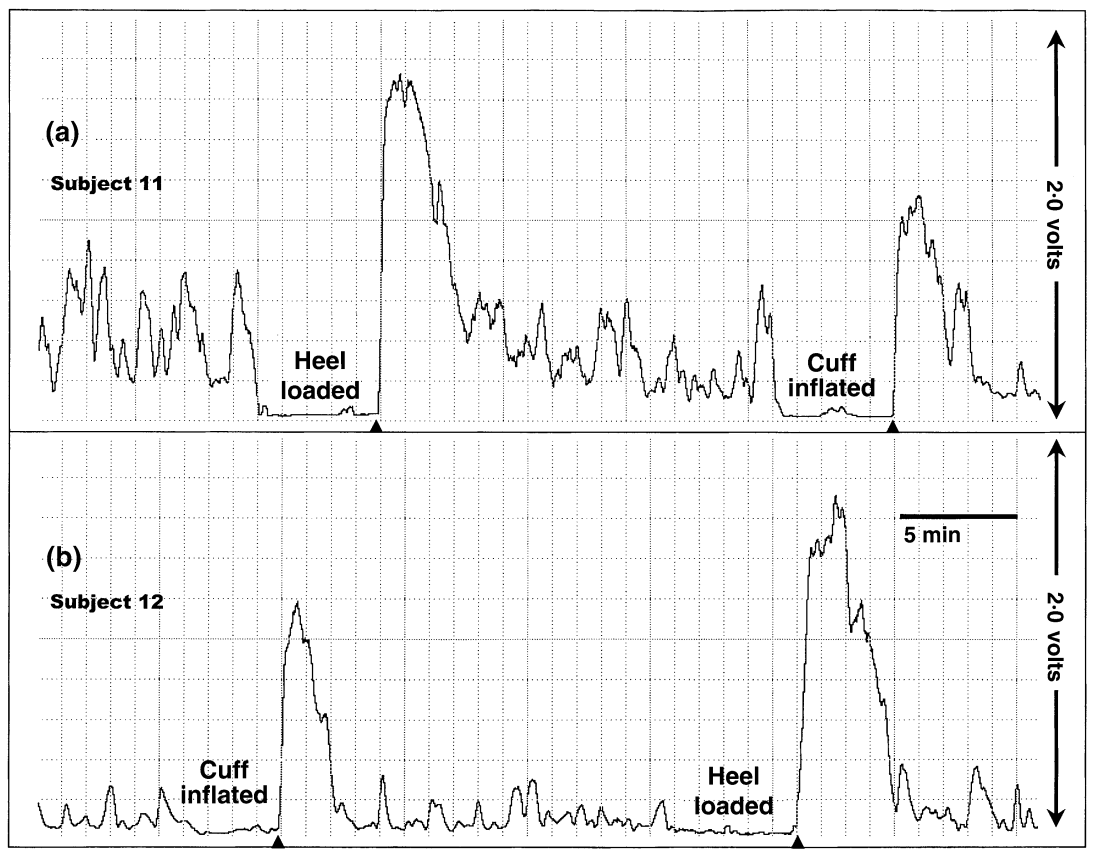

Figure 2 Typical responses. (a) Load then occlusion sequence. (b) occlusion then load sequence. Arrowheads denote offloading and cuff release. Vertical axis is laser-Doppler skin blood flow. 
Heel pressure causes greater hyperaemia than occlusion, H. N. Mayrovitz et al. 357

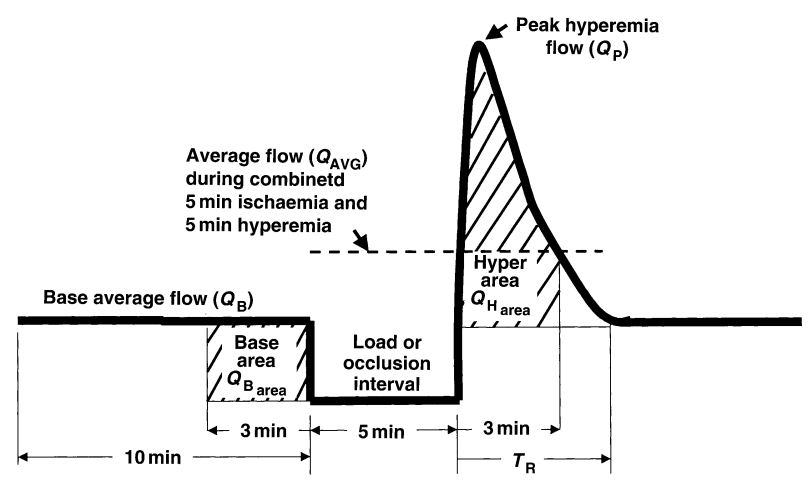

Figure 3 Response parameters.

3-min of hyperaemia (Fig. 3) and the hyperaemia to base area ratio $\left(\mathrm{QH}_{\text {area }} / \mathrm{QB}_{\text {area }}\right)$ determined. A second index of hyperaemia magnitude is the ratio of the peak hyperaemic flow $Q_{P}$, to $Q_{B}$. Hyperaemia duration time was taken as the time for hyperaemia to recover $\left(T_{R}\right)$ to a value equal to $Q_{B}$. For each parameter $\left(Q_{A V G} / Q_{B}\right.$, hyper/base, $Q_{P} / Q_{B}$ and $\left.T_{R}\right)$ direct heel loading versus cuff compression induced responses for each parameter $\left(\mathrm{Q}_{\mathrm{P}} / \mathrm{Q}_{\mathrm{B}}, \mathrm{Q}_{\mathrm{AVG}} / \mathrm{Q}_{\mathrm{B}}, \mathrm{QH}_{\text {area }} / \mathrm{QB}_{\text {area }}\right.$ and $\left.\mathrm{T}_{\mathrm{R}}\right)$ were compared using paired t-tests. Numerical data is presented as mean \pm SEM.

\section{Results}

\section{Baseline and flow-stoppage}

Baseline SBF for the total group $(n=27)$ was $0.83 \pm 0.14 \mathrm{~V}$ (range $0 \cdot 09-2 \cdot 61)$ being less for females $(n=15)$ than for males $(0.60 \pm 0.17 \mathrm{~V}$ versus $1.15 \pm 0.21 \mathrm{~V}, \quad \mathrm{P}<0.05)$. SBF during the 5 -min flow stoppage manoeuvres (direct loading versus ankle compression) were not different $(0.044 \pm 0.008$ versus $0.040 \pm 0.007)$. For direct heel loading, absolute IP was $123 \pm 7 \mathrm{mmHg}$. The ratios of IP to diastolic, mean and systolic pressures were respectively $1.61 \pm 0.08,1.33 \pm 0.06$ and $1 \cdot 00 \pm 0 \cdot 05$.

\section{Hyperaemic responses}

There were no significant differences in any of the response parameters between genders. Male and female data was thus pooled and reported for the entire group. All hyperaemic response parameters were significantly $(\mathrm{P}<0.001)$ greater following direct heel loading as compared with ankle occlusion flow stoppage as detailed in Table 1 .

\section{Discussion}

The main new finding of this study is the discovery of a very significant difference in blood perfusion hyperaemic responses to equal durations of heel skin blood flow stoppage that depend on how flow decrements are produced. Direct heel loading for 5 min results in a significantly greater hyperaemia magnitude
Table 1 Hyperemic responses: direct loading versus Ankle occlusion.

\begin{tabular}{lccc}
\hline Parameter & Heel loading & Ankle occlusion & $P$-value \\
\hline $\mathrm{Q}_{\mathrm{P}} / \mathrm{Q}_{\mathrm{B}}$ & $8 \cdot 20 \pm 1.32$ & $4.68 \pm 0.80$ & $<0.001$ \\
$\mathrm{Q}_{\mathrm{AVG}} / \mathrm{Q}_{\mathrm{B}}$ & $1 \cdot 87 \pm 0.23$ & $0.92 \pm 0 \cdot 11$ & $<0.001$ \\
$\mathrm{QH}_{\text {area }} / \mathrm{QB}_{\text {area }}$ & $4.70 \pm 0.65$ & $1.95 \pm 0 \cdot 29$ & $<0.001$ \\
$\mathrm{~T}_{\mathrm{R}}(\mathrm{s})$ & $352 \pm 39$ & $181 \pm 14$ & $<0 \cdot 001$ \\
\hline
\end{tabular}

$Q_{P}$ is peak hyperemic flow, $Q_{B}$ is average 10 min baseline no-load flow, $\mathrm{Q}_{\mathrm{AVG}}$ is $10 \mathrm{~min}$ average flow for combined $5 \mathrm{~min}$ of flow reduction and 5 min of hyperaemia, $\mathrm{QB}_{\text {area }}$ is the 3 min flow-time area immediately before load or occlusion release and $\mathrm{QH}_{\text {area }}$ is the corresponding area for hyperaemia, $T_{R}$ is the hyperaemia recovery time.

and duration as compared with blood flow stoppage caused by proximal cuff-compression for the same duration. Possible implications of this finding are that the hyperaemia is responding to either different actual levels of tissue ischaemia or is responding to more than just a prior interval of ischaemia.

Although this study was designed to determine if different heel hyperaemic responses occur subsequent to two different forms of flow stoppage, it is useful to discuss some possible mechanisms. The central features needing accounting are the approximately twofold greater magnitude and duration of the hyperaemic response subsequent to direct heel loading as compared with occlusion-induced flow stoppage. Several physical differences are associated with the two different methods. During direct loading, local tissue is compressed, contents of the blood vessels experiencing the load are expelled, transmural pressure of vessels decrease and vessels become fully or partially collapsed. Contrastingly, during proximal occlusion, vessels maintain their blood content, transmural pressure in postcapillary vessels increase, and vessels distend. One or more of these differences may account for the observed differences subsequent to release of load or occlusion as considered below.

\section{Mechanical factors}

From a mechanical standpoint, refilling of previously emptied vessels during loading would likely be associated with a greater initial (peak) hyperaemic inflow although it is difficult to estimate the amount of increase because the expelled volume is not known. However, as normal capillary refill times are only 3-5 s (Schriger \& Baraff, 1988; Raichur et al., 2001), refilling would not likely explain the increased duration of the load dependent hyperaemia. Another mechanically linked possibility is that tissue recovery after 5 -min of compression might be delayed thereby limiting vessel re-expansion rate and extending refill time. However, previous observations of heel tissue recovery in which heels were loaded with a range of pressures and durations argue against this as a significant factor (Mayrovitz \& Smith, 1998). Another mechanical factor that might conceivably render the postload hyperaemia peak greater than the postocclusion hyperaemia is the slight downward rotation of the foot when the heel support pressure was reduced to zero. It has 
been observed (Radegran \& Saltin, 2003) that passive knee extension can cause a blood flow increase to the quadriceps. However, as in the present case the full limb remained supported down to the ankle during the pressure relief manoeuvre, this mechanical event would not likely explain the present findings. Another consideration is the possible effect of heel skin temperature differences during the loading and occlusive manoeuvres. Blood flow to the heel region was in both cases reduced to zero, thereby similarly affecting heat conduction via blood to the laser-Doppler monitored region. However, it is possible that because the heel was in contact with the support surface during loading there was a thermal insulating effect not present during the occlusion manoeuvre. This conceivably could have resulted in less of a decrease in skin temperature as compared with the occlusion manoeuvre. Although no significant differences in skin temperature at the temperature monitored medial heel site were noted between flow stoppage manoeuvres, the possibility that the temperature of the posterior heel skin fell slightly less during loading than occlusion can not be excluded on the basis of the present measurements.

\section{Physiological factors}

Additional possibilities to explain the larger hyperaemia caused by direct loading may be attributable to pressure effects on underlying tissue or blood vessels. Trauma, with an associated inflammatory-like response is unlikely involved as the forces on the heel are no greater than usually experienced under a variety of normal activities. However, concentrated heel forces transmitted to underlying blood vessels may trigger release of vasoactive substances that reveal their effect during the hyperaemic phase. This possibility is consistent with recent work that showed that increasing external pressure surrounding isolated arterioles resulted in a reactive diameter dilation that mimicked reactive hyperaemia features (Koller \& Bagi, 2002). This response was dependent on nitric oxide release apparently triggered by endothelial cell distortion. Further possibilities may relate to possible impacts on arteriolar myogenic responses (Schubert \& Mulvany, 1999) in which a reduced arteriolar transmural pressure triggers a myogenic-related vasodilation (Falcone et al., 1991) which, in the present case may be exacerbated by a concomitant decrease in oxygen (Liu et al., 2002). This myogenic-related vasodilation during the loading interval may thus set the stage for the larger hyperaemia upon load removal. There is also evidence that emptying of venous vessels is associated with arteriolar vasodilation (Tschakovsky \& Hughson, 2000). Since such venous emptying occurs with direct compression but not occlusion, this reflex may be involved in the observed greater hyperaemia subsequent to direct heel loading.

\section{Differences in tissue ischaemia?}

Although the extent and duration of blood flow stoppage during loading and occlusion was the same, differences in potential tissue oxygen availability may render tissue less ischaemic in the case of the proximal occlusion. Recent measurements have convincingly shown that epidermis and upper parts of the dermis are mainly supplied with oxygen from the atmosphere with capillary oxygen playing a minor role (Stucker et al., 2000; Stucker et al., 2002). With proximal occlusion, both environmental oxygen and limited capillary oxygen are available for the tissue. Conversely, direct loading essentially removes both of these potential sources of tissue oxygenation. Thus, during occlusion the $\mathrm{O}_{2}$ consumption of skin may be partially supplied from environmental oxygen and to a lesser extent by stagnant, but still partially oxygenated blood, whereas neither of these sources would be available during direct tissue loading. Under these conditions it is likely that the $\mathrm{P}_{\mathrm{O}_{2}}$ in tissue under direct compression would fall more than for proximal occlusion. Reduced tissue $\mathrm{P}_{\mathrm{O}_{2}}$ is associated with both direct (Blitzer et al., 1996) and conducted (Collins et al., 1998) hypoxic vasodilatory effects which may in part account for the present observations. Clearly, more studies are needed to further clarify the mechanisms responsible for the observed differences in hyperaemic responses.

\section{References}

Allman RM. Pressure ulcer prevalence, incidence, risk factors, and impact. Clin Geriatr Med (1997); 13: 421-436.

Blitzer ML, Lee SD, Creager MA. Endothelium-derived nitric oxide mediates hypoxic vasodilation of resistance vessels in humans. Am J Physiol (1996); 271: H1182-H1185.

Byers PH, Carta SG, Mayrovitz HN. Pressure ulcer research issues in surgical patients. Adv Skin Wound Care (2000); 13: 115-121.

Cheneworth CC, Hagglund KH, Valmassoi B, Brannon C. Portrait of practice: healing heel ulcers. Adv Wound Care (1994); 7: 44-48.

Collins DM, Mccullough WT, Ellsworth ML. Conducted vascular responses: communication across the capillary bed. Microvasc Res (1998); 56: 43-53.

Evans D, Land L, Geary A. A clinical evaluation of the Nimbus 3 alternating pressure mattress replacement system. J Wound Care (2000); 9: 181-186.

Falcone JC, Davis MJ, Meininger GA. Endothelial independence of myogenic response in isolated skeletal muscle arterioles. Am J Physiol (1991); 260: H130-H135.

Goetz LL, Brown GS, Priebe MM. Interface pressure characteristics of alternating air cell mattresses in persons with spinal cord injury. J Spinal Cord Med (2002); 25: 167-173.

Kemp MG, Keithley JK, Smith DW, Morreale B. Factors that contribute to pressure sores in surgical patients. Res Nurs Health (1990); 13: 293301.

Koller A, Bagi Z. On the role of mechanosensitive mechanisms eliciting reactive hyperemia. Am J Physiol (2002); 283: H2250-H2259.

Kosiak M. A mechanical resting surface: its effect on pressure distribution. Arch Phys Med Rehabil (1976); 57: 481-484.

Liu Y, Harder DR, Lombard JH. Interaction of myogenic mechanisms and hypoxic dilation in rat middle cerebral arteries. Am J Physiol Heart Circ Physiol (2002); 283: H2276-H2281.

Mayrovitz HN. Assessment of human microvascular function. In: Analysis of Cardiovascular Function (eds Drzewiecki, G, Li, J) (1998a), pp. 248273. Springer, New York.

Mayrovitz HN. Pressure and blood flow linkages and impacts on pressure ulcer development. Adv Wound Care (1998b); 11: 4. 
Mayrovitz HN, Leedham JA. Laser-doppler imaging of forearm skin: perfusion features and dependence of the biological zero on heatinduced hyperemia. Microvasc Res (2001); 62: 74-78.

Mayrovitz HN, Sims N. Effects of different cyclic pressurization and relief patterns on heel skin blood perfusion. Adv Skin Wound Care (2002); 15: 158-164.

Mayrovitz HN, Smith J. Heel-skin microvascular blood perfusion responses to sustained pressure loading and unloading. Microcirculation (1998); 5: 227-233.

Mayrovitz HN, Smith JR. Adaptive skin blood flow increases during hipdown lying in elderly women. Adv Wound Care (1999); 12: 295-301.

Mayrovitz HN, Smith J, Delgado M, Regan MB. Heel blood perfusion responses to pressure loading and unloading in women. Ostomy Wound Manage (1997); 43: 16-20, 22, 24, passim.

Mayrovitz HN, Macdonald J, Smith JR. Blood perfusion hyperaemia in response to graded loading of human heels assessed by laser-Doppler imaging. Clin Physiol (1999); 19: 351-359.

Meehan M. Multisite pressure ulcer prevalence survey. Decubitus (1990); 3: 14-17.

Newton $\mathrm{H}$. The theracute alternating pressure replacement mattress. $\mathrm{Br} \mathrm{J}$ Nurs (2001); 10: 883-886.

Papantonio CT, Wallop JM, Kolodner KB. Sacral ulcers following cardiac surgery: incidence and risks. Adv Wound Care (1994); 7: 24-36.

Radegran G, Saltin B. Muscle blood flow at onset of dynamic exercise in humans. Am J Physiol (2003); 274: H314-H322.

Raichur DV, Aralihond AP, Kasturi AV, Patil DH. Capillary refill time in term neonates: bedside assessment. Indian J Pediatr (2001); 68: 613615.
Regan MB, Byers PH, Mayrovitz HN. Efficacy of a comprehensive pressure ulcer prevention program in an extended care facility. Adv Wound Care (1995); 8: 49, 51-42, 54-45.

Rendell MS, Wells JM. Ischemic and pressure-induced hyperemia: a comparison. Arch Phys Med Rehabil (1998); 79: 1451-1455.

Rithalia SV, Gonsalkorale M. Quantification of pressure relief using interface pressure and tissue perfusion in alternating pressure air mattresses. Arch Phys Med Rehabil (2000); 81: 1364-1369.

Schoonhoven L, Defloor T, Grypdonck MH. Incidence of pressure ulcers due to surgery. J Clin Nurs (2002); 11: 479-487.

Schriger DL, Baraff L. Defining normal capillary refill: variation with age, sex, and temperature. Ann Emerg Med (1988); 17: 932-935.

Schubert R, Mulvany MJ. The myogenic response: established facts and attractive hypotheses. Clin Sci (Lond) (1999); 96: 313-326.

Stucker M, Struk PA., Hoffmann K, Schulze L, Rochling A, Lubbers DW. The transepidermal oxygen flux from the environment is in balance with the capillary oxygen supply. J Invest Dermatol (2000); 114: 533540 .

Stucker M, Struk A, Altmeyer P, Herde M, Baumgartl H, Lubbers DW. The cutaneous uptake of atmospheric oxygen contributes significantly to the oxygen supply of human dermis and epidermis. J Physiol (2002); 538: 985-994.

Tourtual DM, Riesenberg LA, Korutz CJ, Semo AH, Asef A, Talati K, Gill $\mathrm{RD}$. Predictors of hospital acquired heel pressure ulcers. Ostomy Wound Manage (1997); 43: 24-28, 30, 32-24, passim.

Tschakovsky ME, Hughson RL. Venous emptying mediates a transient vasodilation in the human forearm. Am J Physiol (2000); 279: H1007H1 014 . 